\title{
Gabriel Soares de Sousa, Mia Couto e Guimarães Rosa nas reflexões do exílio
}

Teresinha Gema Lins Brandão Chaves ${ }^{1}$

RESUMO: A partir de recortes das obras Tratado Descriptivo do Brasil, de Gabriel Soares de Sousa; Terra Sonâmbula, de Mia Couto e Cara-de-bronze, de Guimarães Rosa, põe-se em prática o mapeamento de territórios que se situam para além daqueles cartografados pela literatura do exílio, tal como sugere Edward Said em seu ensaio Reflexões sobre o exílio.

ABSTRACT: To come from Tratado Descriptivo do Brasil, by Gabriel Soares de Sousa; Terra Sonâmbula, by Mia Couto e Cara-de-bronze, by Guimarães Rosa this article analysis the expansion of the experience's territory that position over those draw for the exile literature as Edward Said suggests in his essay Reflexões sobre o exílio.

PALAVRAS-CHAVE: Edward Said; literatura do exílio.

KEYWORDS: Edward Said; exile literature.

Vou voltar para o meu lugar foi lá e é ainda lá

que eu hei de ouvir cantar uma sabiá, cantar uma sabiá. Tom Jobim e Chico Buarque

Edward Said, em seu ensaio Reflexões sobre o exílio, expõe seu pensamento sobre o nostálgico mundo de poetas e escritores exilados, bem como de refugiados, deslocados e imigrantes em massa produzidos pela "guerra moderna, o imperialismo e as ambições quase teológicas dos governantes totalitários”. ${ }^{2}$

Partindo de sua própria experiência, suas ponderações vão levando cada vez mais o leitor aos labirintos da alma dilacerada pela

\footnotetext{
${ }^{1}$ Doutoranda em Estudos Comparados de Literaturas de Língua Portuguesa, FFLCHUSP. Pesquisa: Corpo de baile, de Guimarães Rosa e diários de viajantes portugueses. E-mail: chavesge@yahoo.com.br.

${ }^{2}$ Edward SAID, Reflexões sobre o exílio, p.47. Doravante, o ensaio Reflexões sobre o exílio será mencionado sob a sigla RSE, seguida do respectivo número de página.
} 
"fratura incurável entre um ser humano e um lugar natal, entre o eu e seu verdadeiro lar” (RSE: 46). No texto desse brilhante pensador, tão entregue às contradições sociais, políticas e humanas, figura-se um espaço de reflexão sobre as visões do exílio na literatura e a realidade dessa condição. Para o autor, "embora seja verdade que a literatura e a história contêm episódios heróicos, românticos, gloriosos e até triunfais da vida de um exilado, eles não são mais do que esforços para superar a dor mutiladora da separação" (Ibid.). E acrescenta: "A moderna cultura ocidental é, em larga medida, obra de exilados, emigrantes, refugiados” (Ibid.).

Num exercício de comparação entre a literatura ocidental do século XX com a produzida em outras épocas, o crítico ressalta:

Em outras épocas, os exilados tiveram visões transnacionais e multiculturais semelhantes, sofreram as mesmas frustrações e aflições, desempenharam as mesmas tarefas elucidativas e criticas _ brilhantemente afirmadas, por exemplo, em The Romantic Exiles [Os exilados românticos], o estudo clássico de E.H. Carr sobre os intelectuais russos do século XIX agrupados em torno de Herzen (RSE: 47).

Referindo-se à "escala do século XX", Said nos convida a pensar nos "territórios de experiência que se situam para além daqueles cartografados pela própria literatura do exílio” (RSE: 48). Assim recomenda:

É preciso pensar nos camponeses refugiados sem perspectiva de voltar algum dia para casa, armados somente com um cartão de suprimentos e um número da agência. (...) É preciso pensar também em Cairo, Beirute, Madagascar, Bangkok, Cidade do México. (...) Para refletir sobre muçulmanos exilados da Índia, haitianos nos Estados Unidos, habitantes de Bikini na Oceania, ou palestinos em todo o mundo árabe, é preciso deixar o modesto refúgio proporcionado pela subjetividade e apelar para a abstração da política de massas. Negociações, guerras de libertação nacional, gente arrancada de suas casas e levada às cutucadas, de ônibus ou a pé, para enclaves em outras regiões: o que essas experiências significam? (RSE: 49). 
É claro que essa imensa massa não é integrada por intelectuais, escritores ou poetas, mas agrupam-se pelo que têm em comum: o obstáculo do retorno para casa e a experiência de permanecer num "estado de ser descontínuo", usando a expressão de Said (RSE: 50). De acordo com suas experiências, esses grupos de homens e mulheres desconhecidos chamados de exilados, emigrados e refugiados foram categorizados de forma significativa nas Reflexões sobre o exílio:

O exílio tem origem na velha prática do banimento. Uma vez banido, o exilado leva uma vida anômala e infeliz, com o estigma de ser um forasteiro (...) Os emigrados gozam de uma situação ambígua. Do ponto de vista técnico, trata-se de alguém que emigra para um outro país. Claro, há sempre uma possibilidade de escolha, quando se trata de emigrar. Funcionários coloniais, missionários, assessores técnicos, mercenários e conselheiros militares podem, em certo sentido, viver em exílio, mas não foram banidos (...) Por outro lado, os refugiados são uma criação do Estado do século XX. A palavra 'refugiado' tornou-se política: ela sugere grandes rebanhos de gente inocente e desnorteada que precisa de ajuda internacional urgente (RSE: 54).

Portanto, os territórios da colonização, das missões religiosas e expedições científicas; os campos de extermínio e das guerras; os acampamentos de camponeses e as regiões pobres atingidas por desastres naturais constituem espaços para a expansão da "cartografia da literatura do exílio" sugerida por Said.

Tendo como pano de fundo alguns desses cenários - lugares onde circulam emigrados, refugiados e exilados _ propomos, neste ensaio, um confronto das obras: Tratado Descriptivo do Brasil de Gabriel Soares de Sousa; Terra Sonâmbula de Mia Couto e Cara-de-bronze de Guimarães Rosa, utilizando o instrumental teórico elaborado por Edward Said.

Gabriel Soares de Sousa, cronista português, autor do Tratado Descriptivo do Brasil em 1587, um dos primeiros depoimentos escritos sobre o Brasil, representa o colonizador que se rende à tentação do exílio no "paraíso" em troca de riqueza, poder e prestígio. Seu projeto inicial de chegar à cabeceira do rio São Francisco, onde deveria 
encontrar metais preciosos sofre sucessivos malogros incluindo a sua própria morte.

Terra Sonâmbula, de Mia Couto, descreve a luta pela sobrevivência dos exilados pela guerra. Errantes dentro de seu próprio país, Muidinga e Kindzu desejam viver em liberdade em seu Moçambique massacrado pela colonização e a guerra civil.

O conto Cara-de-bronze, de Guimarães Rosa é a própria poesia do exílio e a representação do “exílio moderno”. Cara-de-bronze, um foragido no sertão, torna-se rico fazendeiro. Tem como último desejo rever as pessoas e as paisagens deixadas para trás. No conto, as "palavras-cantigas" trazidas pelo vaqueiro Grivo, atravessam fronteiras, rompem as barreiras do pensamento e manifestam sua universalidade.

\section{O exílio do colonizador}

O segundo livro do Antigo Testamento descreve o Êxodo, palavra de origem grega que quer dizer saída. Fugindo das perseguições que sofriam, após quatrocentos e trinta anos vivendo no Egito, os judeus partiram a pé em busca da "terra prometida". Assim a Bíblia relata:

Partiram pois os filhos de Israel (...) perto de seiscentos mil homens afora os meninos. Foram eles seguidos de uma inumerável multidão do vulgo, e levavam consigo uma infinidade de ovelhas, de rebanhos, e de animais de todas as castas. Cozeram a farinha, que havia tempo tinham trazido amassada do Egito (...) porque os egipcios lhes tinham dado tanta pressa a partir, que lhes não deram tempo a meter-lhes fermento, nem a preparar nada de comer3.

Do ponto de vista sociológico e histórico, o Êxodo tornou-se importante documento por registrar a primeira atitude anti-semita da história. A suposição de que um povo numeroso e rico ameaçaria a segurança de uma nação vai se repetir na história moderna.

No teatro grego, o êxodo se referia ao último episódio da tragédia, após o canto de despedida do corpo e no teatro romano, correspondia à

${ }^{3}$ Bíblia Sagrada, Ex 12, 37-39. 
parte final de uma comédia, ou episódio cômico subseqüente à representação de uma tragédia ${ }^{4}$. Poderíamos perguntar: o último episódio de uma tragédia - o êxodo, a saída - seria a morte? Retornando às Reflexões do exílio, Said afirma que "tal como a morte, mas sem sua última misericórdia, [o exílio] arrancou milhões de pessoas do sustento da tradição, da família, da geografia” (RSE: 47).

Na obra da conquista e colonização da América, muitos emigrados passaram pela experiência do exílio e morreram sem o esperado retorno à pátria. É o caso do colonizador português Gabriel Soares de Sousa. Nascido em Portugal em 1540, viajando na armada de Francisco Barreto, fixou-se na Bahia em 1570, montando um engenho em Jaguaribe. Sua obra o Tratado Descriptivo do Brasil em 1587, contém as lembranças anotadas durante os 17 anos que residiu no Brasil, onde descreve com realismo a geografia, história, zoologia, etnografia e medicina dos indígenas, dentre outros campos. Herdou de seu irmão, morto vítima de febres, o itinerário da exploração de minas nos sertões da Bahia e Minas. Em fins de agosto de 1584, requer à Coroa, concessões e privilégios para a continuidade do projeto de exploração do sertão. Conforme notícias biográficas da História geral do Brasil, como houvesse dilação no despacho de seu requerimento, de volta à Europa em 1587, com o objetivo de recomendar-se, ofereceu a D.Christóvão de Moura, influente estadista no governo, o "precioso escripto a cerca do Brasil”. O despacho ocorreu em meados de dezembro de 1590. Em abril de 1591 retorna ao Brasil trazendo uns trezentos e sessenta homens ${ }^{5}$.

É provável que a dilação no despacho tenha sido proporcional à dilatada lista de pedidos, pois conforme documentos, as concessões obtidas pelo mesmo Soares "reduziram-se" a

uma carta régia ao governador do Brasil, afim de que fossem postos às suas ordens duzentos índios frecheiros; (...) Que o mesmo Gabriel Soares de Sousa (...) teria o direito de nomear, por seu fallecimento, um sucessor que gozaria dos mesmos títulos e

${ }^{4}$ HOLANDA, 1975, p. 601.

5 SOUSA, 1938, p. XVIII. 
poder (...) em ter faculdade de prover todos os officios da justiça e da fazenda em seu districto (...) em lhe ser concedido, para quatro cunhados e dois primos (...) o habito de Christo, com 50 rs. e o foro de fidalgo e moradia (...) em poder conceder o foro de cavalleiros fidalgos até cem pessoas dos do seu séqüito (...) em poder fazer promessas de mais recompensas aos que se distinguissem (...) em lhe ser facilitado tirar das prisões, para levar consigo, os condenados a degredo que escolhesse, sendo de officios, mechanicos, mineiros, etc (...) obteve (...) uma ordem para (...) se lhe dar embarcação, e mantimento (...) e outra para o governador do Brasil lhe dar cincoenta quintaes de algodão em caroço (...) afim de se fazerem armas, para os que o deviam acompanhar á (sic) nova conquista ${ }^{6}$.

Sérgio Buarque de Holanda, em Raizes do Brasil, afirma: “o que o português vinha buscar era, sem dúvida, riqueza, mas riqueza que custa ousadia, não riqueza que custa trabalho7". O espírito aventureiro ignora fronteiras, "vive dos horizontes distantes"8. E na ânsia de títulos, honras e riquezas fáceis, procuram recriar o meio de sua origem. Quanto a esse último aspecto, Said observa: "para o exilado, os hábitos de vida, expressão ou atividade no novo ambiente ocorrem inevitavelmente contra o pano de fundo da memória dessas coisas em outro ambiente" (RSE: 59).

Pois bem, o projeto audacioso de Soares de chegar às cabeceiras do rio São Francisco onde encontraria as minas de acordo com o roteiro de seu irmão, não se concretizou. Depois de sofrer sucessivos malogros - naufrágio da urca com a morte de parte da tripulação, febres, animais perdidos e mordidos por morcegos, ciladas dos gentios, mordidas de cobras, cheias súbitas dos rios, nevoeiros e frio - a expedição chega a uma das grandes vertentes do São Francisco. Gabriel Soares já fraco e doente falece pouco depois. Não deixou herdeiros legítimos e nem sucessor nomeado para substituí-lo na expedição. Sabe-se, porém, que após sua morte, o governador ordenou o regresso de toda a expedição e apoderou-se de todos os roteiros, vindo a usá-los em proveito próprio, após deixar o governo, obtendo ainda os mesmos

\footnotetext{
6 Ibidem, p. XIX, XX.

7 HOLANDA, 2003, p. 49.

8 Ibidem, p. 44.
} 
privilégios e concessões outorgados a Soares acrescidos de outros mais. ${ }^{9}$

Curioso foi o extenso testamento inscrito no "Aditamento" do Tratado Descriptivo de Gabriel Soares, no qual recomenda, por vezes ordena, que se rezem inumeráveis ofícios e missas diárias "para enquanto o mundo durar", por intenção de sua alma. Deixa esmolas e doações vultosas para instituições religiosas. Pede uma campa, no hábito de um mosteiro com o letreiro: Aqui jaz um peccador, qualquer que seja o país em que venha falecer. Parece-nos que os dados do imaginário europeu (“Última Tule”, “Jardim do Éden”, "Paraíso Terrestre") foram preponderantes na elaboração do documento.

As observações de Gabriel Soares inscritas no seu diário são animadas pela visão do colonizador acerca do Novo Mundo e sua adaptação num ambiente totalmente novo e distante da sua realidade.

\section{O exílio do colonizado}

Em Terra sonâmbula, de Mia Couto, no primeiro caderno de Kindzu intitulado "O tempo em que o mundo tinha a nossa idade", o menino Kindzu escreve:

... meu pai sofria de sonhos (...) recebia notícias do futuro por via dos antepassados. Dizia tantas previsões que nem havia tempo de provar nenhuma (...) Nesses anos ainda tudo tinha sentido: a razão deste mundo estava num outro mundo inexplicável. Os mais velhos faziam a ponte entre esses dois mundos (...) Recordo meu pai nos chamar um dia (...) Anunciava um fato: a Independência do país. Nessa altura nem sabíamos o verdadeiro significado daquele anúncio. Mas havia na voz do velho uma emoção tão funda, parecia estar ali a consumação de todos os seus sonhos (...) O tempo passeava com mansas lentidões quando chegou a guerra. Meu pai dizia que era confusão vinda de fora, trazida por aqueles que tinham perdido seus privilégios. No princípio só escutávamos as vagas novidades, acontecidas no longe. Depois os tiroteios foram chegando mais perto e o sangue foi enchendo nossos medos (...) Aos poucos, eu sentia a nossa

9 SOUSA, 1938, p. XXIV. 
família quebrar-se como um pote lançado ao chão. Ali onde eu sempre tinha encontrado meu refúgio já não restava nada ${ }^{10}$.

Nesse primeiro capítulo, Mia Couto sintetiza com realismo e poesia, através da voz de um menino, as "vozes anoitecidas" dos colonizados de seu país. A partir daí, a história do menino Kindzu, desenrola-se em mais onze cadernos, aonde o narrador vai descrevendo um mundo cuja trajetória e ideais de seus personagens são marcados pela guerra e a miséria. Entrecortando esse relato, a história do menino Muidinga, leitor dos diários, num pacto de solidariedade, vai ser uma repetição espontânea da história do outro, confirmando assim, os desejos e sonhos de heróis desconhecidos, exilados em seu próprio país pela guerra, para os quais segundo Said "foram criadas as agências da ONU" (RSE: 49).

A guerra da Independência das colônias e a guerra civil que massacraram os povos africanos no último século e tão veemente discutidas por Frantz Fanon, foram muito bem sintetizadas por José Luís Cabaço e Rita Chaves no ensaio Frantz Fanon: colonialismo, violência, identidade e cultura, onde comentam que a visão de Fanon acerca da deslocação vivenciada pelos povos colonizados se fixa detalhadamente em dois pontos: "a energia desorganizadora desse fenômeno na vida das pessoas" e a "alienação' na qual os aspectos psicossociais e culturais se sobrepõem aos aspectos econômicos ${ }^{11}$ ".

Como médico psiquiatra num hospital argelino e pensador social, Fanon percebe, através da diáspora árabe, que o homem "permanentemente estrangeiro em seu próprio país, vive um estado de absoluta despersonalização". Tentar conduzir o indivíduo de volta ao seu devido lugar era impossível dentro da estrutura social existente na Argélia ${ }^{12}$. Seguindo o pensamento de Fanon, Bhabha postula a idéia de que o processo de construção da identidade em contextos coloniais é algo conflitante e ambíguo, pois para o crítico "a identidade é construída

\footnotetext{
10 COUTO, 1995, p. 17-18-19.

${ }^{11}$ CABAÇO; CHAVES, In ABDALA JUNIOR (org.), 2004, p. 79.

12 Ibidem, p. 77.
} 
nas fissuras, nas travessias e nas negociações que ligam o interno e o externo, o público e o privado, o psíquico e o político ${ }^{13}$ ”.

Em Terra Sonâmbula, Muidinga e o tio fogem da guerra. "Andam bambolentos como se caminhar fosse seu único serviço desde que nasceram. Vão para lá de nenhuma parte, dando o vindo por não ido, à espera do adiante. Vão na ilusão de mais além, haver um refúgio tranqüilo ${ }^{14 "}$. Destituídos de identidade e de referências, deslocados de tudo e de todos, tornam-se sujeitos solitários e alienados. O filósofo Theodor Adorno sustentava que "o único lar realmente disponível agora, embora frágil e vulnerável, está na escrita15. Kindzu, menino sonhador, cultor de lembranças, através da escrita, acende a história de seu país e o autor de Terra sonâmbula sabe que esta é a única forma de falar sobre "uma perversa fabricação de ausência - a falta de uma terra toda inteira, um imenso rapto de esperanças praticado pela ganância dos poderosos 16". Por essa razão Kindzu escreve: "no fim desses escritos, serei de novo uma sombra sem voz ${ }^{17}$ ". No final da narrativa, depois de sofrida errância, de perdas e derrotas, sufocado num tremendo cansaço, Kindzu resolve embarcar num "machibombo" e retornar à sua aldeia. Tem um último sonho: vê um "autocarro" queimado. Continua, então seu sonh'escrito: "De repente, a cabeça me estala em surdo baque (...) Vacilo, vencido por súbito falecimento (...) Deixo cair ali a mala onde trago os cadernos ${ }^{18}$ ". Logo após, Muidinga e o tio caminham pela estrada. Instalam-se num autocarro incendiado. Encontram espalhados no chão os cadernos. Muidinga começa a ler. E assim, os sonhos dos meninos se misturam, as estórias se repetem, as vozes se calam no, até então, imutável destino dos refugiados pobres.

Ao amanhecer do dia 26 de dezembro de 2004, um maremoto arrasou a costa de países pobres da Ásia e África dando início a um outro capítulo na história dos deslocados. Desta vez, vítimas de um

\footnotetext{
${ }^{13}$ Apud SOUZA, In ABDALA JUNIOR (org.), 2004, p. 124.

14 COUTO, 1995, p. 9.

15 Apud SAID, 2003, p. 58.

16 COUTO, 2001, discurso entrega prêmio Mário Antônio.

17 Idem, 1993, p. 17.

18 Ibidem, p. 245.
} 
desastre ambiental e com uma "singela" particularidade: turistas ricos do Primeiro Mundo e nativos pobres foram arrancados de seus hotéis de luxo e de seus lares pobres pela fúria das águas. Subitamente perdidos, deslocados, sepultaram, em valas comuns, os seus mortos.

\section{Guimarães Rosa e a poesia do exilio}

Em outubro de 2004, quando o Comitê do Prêmio Nobel da Paz anunciou o nome de Wangari Maathai, ambientalista queniana, como eleita para o prêmio da Paz, as opiniões se dividiram. Enquanto os ambientalistas aplaudiam o importante serviço que o Nobel prestava à sociedade, ao destacar a questão ambiental como prioritária para a paz, o Comitê enfrentava resistências por contrariar as posições dos segmentos que consideram os aspectos militares, políticos, de conflitos e segurança desvinculados da base ecológica que os sustenta.

Em dezembro de 2004, a natureza dá uma resposta ao impasse. As placas tectônicas da terra também se dividem no Oceano Índico, provocando uma catástrofe com milhares de mortos, feridos e desabrigados. Entre os noticiários, um nos chama a atenção: nas reservas ambientais atingidas pelo maremoto, nenhum animal morreu. A ciência explica: os animais possuem mecanismos de defesa mais desenvolvidos que o homem. Através do olfato, da audição e do tato conseguem detectar as alterações da temperatura, pressão atmosférica e umidade de seu habitat.

Diante da inflexível revolução da natureza, o homem se vê obrigado a repensar a sua relação com o ambiente natural. Portanto, cabe aqui destacar o conto "Cara-de-bronze" de Guimarães Rosa em que a relação homem e natureza acontece de forma exemplar e a tentativa de recuperação de uma paisagem perdida na memória se torna emblemática.

Para uma análise do conto seguiremos a linha de pensamento do crítico Edouard Glissant, para quem "a busca do conhecimento se dá 
através do pensamento poético" procurando, assim, traçar um "rizoma" com o mundo ${ }^{19}$.

O Cara-de-bronze é um jovem maranhense. Pensando ter matado o pai, foge de sua terra natal para o sertão de Minas. Concentrado na ambição e no trabalho, se torna rico fazendeiro. "Triste, fechado, exilado, imobilizado pela paralisia (que é a exteriorização de uma como que 'paralisia da alma'), parece misterioso ${ }^{20 " . ~ D e s e j a n d o ~ r e v e r ~ s u a ~ t e r r a, ~}$ escolhe o vaqueiro Grivo, para uma expedição cujo objetivo era "captar a poesia das paisagens e lugares, deixados para trás, para, depois, ouvir dele, trazidas por ele, por esse especialíssimo intermediário, todas as belezas e poesias de lá ${ }^{21}$ ”. Aqui, invocamos, mais uma vez, Said, quando afirma que "por mais que tenham êxito, os exilados são sempre excêntricos que sentem sua diferença (ao mesmo tempo que, com freqüência, a exploram) como um tipo de orfandade” (RSE: 55). Dessa maneira, o vaqueiro escolhido reúne um acervo, que apresentado ao velho fazendeiro, extrapola o texto. Tudo que se refere à natureza da terra natal ganha destaque e se converte em proposta poética: centenas de bichos e plantas, os rios, as chuvas, o céu, o sol, a lua, as estrelas, a poeira, o vento, o calor, o frio e as veredas. O mundo ficcional da ambição, do trabalho e da riqueza implantado no sertão é suplantado pelas tintas carregadas pelas cores da paisagem nativa e sua vigorosa universalidade. Como expressão poética de um topos da experiência humana, o exílio de "Cara-de-bronze" se encerra em curtos e enigmáticos diálogos:

GRIVO: (de repente começando a falar depressa, comovido): Ele, o Velho, me perguntou: - "Você viu e aprendeu como é tudo, por lá?" - perguntou com muita cordura. Eu disse: - k "Nhor vi." (...)

GRIVO:... Ele, o Velho, disse, acendido: — "Eu queria alguém que me abençoasse..." - ele disse. Aí meu coração tomou tamanho. TADEU: Então, que foi que ele fez, então?

\footnotetext{
19 Apud ROCHA, 2001, p. 22.

20 ROSA, 1981, p. 60.

${ }^{21}$ Idem.
} 
GRIVO: Chorou pranto.22

O conto de Rosa também nos remete a outro conceito de Glissant: a "Errância Moderna", que se contrapõe à errância conquistadora, errância da "descoberta", uma vez que transforma o território em "lugar cultural vivido como consentimento ou como sofrimento ${ }^{23}$ ". Poderíamos dizer ainda que, de sua própria errância o escritor Guimarães Rosa se fez cultor e defensor da natureza. E fez da natureza o "lugar cultural" de sua obra. Do "lugar cultural" traçou o "rizoma" com o mundo.

Retornamos, enfim, a Said e sua cartografia dos exilados. Nela inserimos o exílio no Brasil de Gabriel Soares, o exílio dos meninos moçambicanos de Mia Couto e dos homens do sertão de Guimarães Rosa. Todos fazem parte do processo histórico, da memória pública, mesmo porque é preciso, segundo Said "esvaziar as pretensões do triunfalismo; lembrar, como Benjamin diz, que a história é quase sempre escrita do ponto de vista do vencedor e que o grande desfile da vitória traz em sua esteira os corpos esquecidos dos vencidos 24 ”.

\section{Referências bibliográficas}

BÍBLIA SAGRADA. Encyclopaedia Britannica Publishers, 1972.

CABAÇO, José Luís; CHAVES, Rita. Frantz Fanon: colonialismo, violência e identidade cultural. In: ABDALA JUNIOR, Benjamin (org.).Margens da cultura: mestiçagem, hibridismo \& outras misturas. São Paulo: Boitempo, 2004.

COUTO, Mia. Terra Sonâmbula. Rio de Janeiro: Nova Fronteira, 1995. . Discurso entrega prêmio Mário Antônio da Fundação Calouste em Lisboa.Disponivel em < http: //www.maderazinco.tropical.co.mz/> acesso em 03.01.05.

HOLANDA, Aurélio Buarque. Novo Dicionário da Língua Portuguesa. Rio de Janeiro: Nova Fronteira, 1975.

HOLANDA, Sérgio Buarque de. Raizes do Brasil. 26 a .ed. São Paulo: Companhia das letras, 2003.

ROCHA, Eunice do Carmo Albergaria. A utopia do diverso: o pensamento glissantino nas escritas de Edouard Glissant e Mia Couto. Universidade de São Paulo. Doutorado em Letras, 2001.

22 ROSA, p. 173.

23 Apud ROCHA, 2001, p. 22.

${ }^{24}$ Apud SAID, p. 251. 
ROSA, Guimarães. No Urubuquaquá, no Pinhém. 9a . ed. Rio de Janeiro: Nova Fronteira, 2001. . João Guimarães Rosa: correspondência com seu tradutor italiano E. Bizzarri. São Paulo: T A Queiroz Editor, Instituto Cultural Ítalobrasileiro, 1981.

SAID, Edward. Reflexões sobre o exílio e outros ensaios. São Paulo: Companhia das Letras, 2003.

SOUSA, Gabriel Soares de. Tratado descriptivo do Brasil em 1587. $3^{\mathrm{a}}$.ed. São Paulo: Companhia Editora Nacional, 1938.

SOUZA, Lynn Mário T Menezes de. Hibridismo e tradução cultural em Bhabha. In: ABDALA JUNIOR, Benjamin (Org.). Margens da cultura: mestiçagem, hibridismo \& outras misturas. São Paulo: Boitempo, 2004. 